\title{
Simple Model for the Theoretical Survey of the Green Roof Thermal Behavior
}

\author{
Dominique Morau ${ }^{1, *}$, Rakotondramiarana Hery Tiana ${ }^{2}$ and Andriamamonjy Ando Ludovic ${ }^{2}$ \\ ${ }^{1}$ Laboratory PIMENT, University of La Reunion 117 Rue du Général Ailleret 97430 Le Tampon REUNION, \\ France \\ ${ }^{2}$ Institute for the Management of Energy (IME), University of Antananarivo, BP 566 Antananarivo 101, \\ Madagascar
}

\begin{abstract}
A green roof is an option for the improvement of a building thermal comfort. The objective of this work is to compare respective behaviors of a green roof and a concrete watertight roof vis-à-vis external requests in wet tropical zones. The canopy being considered as uniform, the electric analogy method was used to establish the mathematical models associated to both studied systems of roof. Based on these models, a Matlab computing code was worked out. It ensues from simulation results that in diurnal period, the green roof concrete support top face temperature is lower than that of the concrete watertight roof top face, whereas in night-period the opposite occurs. These results which highlight the energy benefit of the green roof are in agreement with the experimental measurement results obtained at the Laboratory PIMENT of the University of La Reunion. Besides, results of sensitivity analysis done with Fourier Amplitude Sensitivity Test enabled to identify a certain number of the most influential parameters of the proposed model. The above mentioned computing code also forms a help tool for the choice of plants to be experimented on the green roof.
\end{abstract}

Keywords: Green roof, building thermal comfort, modelling, computing code, sensitivity analysis, wet tropical zone, solar energy.

\section{INTRODUCTION}

Natural cooling techniques have been used over the centuries and their application has started to spread throughout the world (Northern hemisphere). The introduction of mechanical air conditioning systems into the building, with their great energy expenditure, has become the basical alternative used to natural cooling.

The number of studies regarding this problematic are developed as ROOFSOL research project [1], which focused on the theoretical and experimental analysis of different roof solutions for cooling in the Mediterranean region, mainly based on evaporative and radiative cooling principles. In the case of Greece, the work of Niachou et al. [2] as well as the study of Spala et al. [3] on the analysis of the green roof thermal properties and energy performance can be cited.

The green roof technology is also able to reduce the energy consumption and to improve the internal comfort during differents seasons, in sites where the climatology is characterized by high temperature and irradiance values during the day [4].

There is a growing literature data regarding the green roof energy balance. An important work has been performed by both experimental and computational methods. For illustration, Cappelli et al.

*Address corresponding to this author at the Laboratory PIMENT, University of La Reunion 117 Rue du Général Ailleret 97430 Le Tampon REUNION, France; Tel: 2622625791 41; Fax: 2622625794 46;

E-mail: dominique.morau@univ-reunion.fr
[5] analyzed the thermal behavior and effectiveness of vegetation covers with different average absorptance for solar radiation and diffuse properties through a finite difference simulation model. Several other studies also referred to the implementation of green roofs on the buildings [6-8].

Few studies were investigated in the Southern hemisphere where the green roof potential as a natural cooling is unknown or poorly known. Wong et al. [9, 10] explored the thermal benefits of a green roof in Singapore through an experimental test done before and after the construction of a rooftop garden.

The objective of this paper is to propose a simple model for the theoretical survey of the green roof cooling in Reunion Island, located in the Indian Ocean and influenced by a tropical humid climate coming from the Southern hemisphere. The green roof potential was explored through the temperature gain.

Besides, Del Barrio [6] proposed a method of statistical linearization to simplify the green roof model proposed in [11]. Indeed, it is important to simplify the green roof model for having a lighter roof computing code to be joined into a bigger code simulating the whole building thermo-hydric behavior.

\section{DESCRIPTION OF THE SYSTEM TO BE MODELLED AND PROBLEM STATEMENT}

Illustrated on Figure (1), a green roof consists generally of three components: the canopy, the ground 


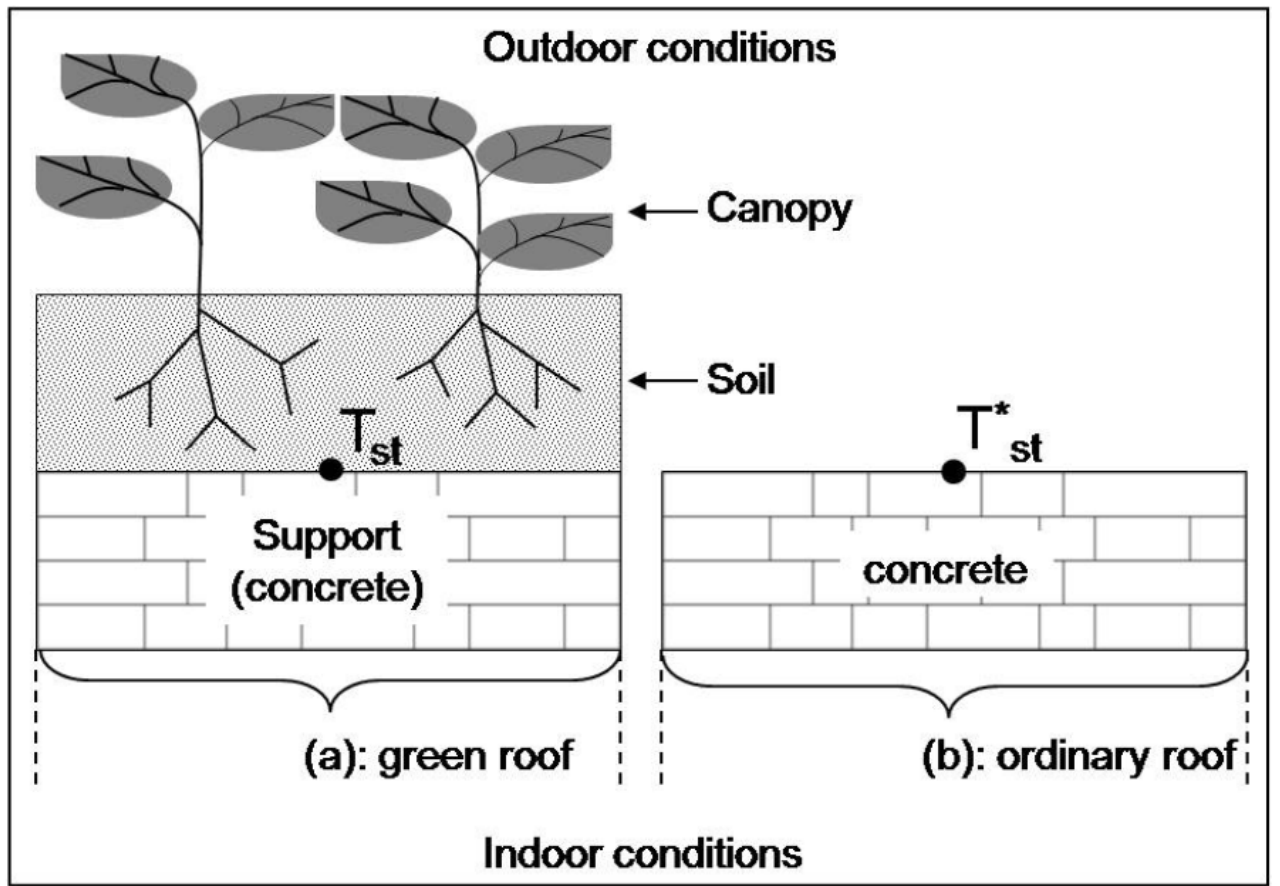

Figure 1: Sketch of a green roof and a concrete-made conventional roof.

for plants growth and the concrete watertight support. In what follows, we mean by "conventional roof" that one consisted only of the concrete watertight support as indicated on Figure (1) $\mathbf{1 b}$. To show the interest of the green roof with regard to the conventional roof, we shall compare the green roof support top face temperature $T_{s t}$ (Figure 1a) and the conventional roof top face temperature $T_{s t}^{*}$ (Figure 1b). We shall observe in particular the temperature gain $\Delta T$ with $\Delta T=T_{s t}^{*}-T_{s t}$.

\section{MATHEMATICAL MODELLING OF BOTH ROOF TYPES}

\subsection{Simplifying Hypotheses for the Green Roof Modelling}

The following hypotheses were adopted to model the green roof: the problem is one-dimensional according to an axis crossing the roof subcomponents layers; the canopy is uniform so as to consider a single temperature for its air and another only one for its foliages; the ground is homogeneous and its humidity is constant; longwave radiations between the support bottom face and the other indoor surfaces are neglected.

\subsection{Thermal Balance Equations of the Green Roof}

Figure (2) describes the various thermal and mass transfers taking place at the roof. By adopting the method of the electric analogies and by applying the
Ohm laws to every temperature node of the soobtained equivalent electric circuit represented on Figure (3), the following thermal balance equations of the green roof can be written per ground area unit:

At the canopy foliage node

$$
\begin{aligned}
d . L A I & (\rho C)_{p} \frac{\partial T_{p}}{\partial t}=h_{r p s k y}\left(T_{s k y}-T_{p}\right) \\
& +h_{r p g}\left(T_{g t}-T_{p}\right)+h_{c v a p}\left(T_{a}-T_{p}\right) \\
& +\left[1-\tau_{s}-\left(1-\tau_{s}\right) \rho_{\infty}\right]\left(1+\tau_{s} \rho_{g}\right) \varphi_{s} \\
& -h_{t r p a}\left(e_{p}-e_{a}\right)
\end{aligned}
$$

At the canopy air node

$$
\begin{aligned}
L_{c}(\rho C)_{a} \frac{\partial T_{a}}{\partial t}= & h_{\text {cvam }}\left(T_{m}-T_{a}\right)+h_{\text {cvap }}\left(T_{p}-T_{a}\right) \\
& +h_{\text {cvag }}\left(T_{g t}-T_{a}\right)
\end{aligned}
$$

At the ground surface node

$$
\begin{aligned}
\frac{1}{2} & L_{g}(\rho C)_{g} \frac{\partial T_{g t}}{\partial t}=h_{c v a g}\left(T_{a}-T_{g t}\right)+h_{r p g}\left(T_{p}-T_{g t}\right) \\
& +\tau_{l} h_{r p s k y}\left(T_{s k y}-T_{g t}\right)+\left(h_{c d g}+h_{d j f g}\right)\left(T_{s t}-T_{g t}\right) \\
& +\left(1-\rho_{g r}\right) \tau_{s} \varphi_{s}+\Lambda\left(T_{g t}\right) \cdot \varphi_{v a p a g}
\end{aligned}
$$

At the support top face node

$$
\begin{array}{r}
\frac{1}{2}\left(L_{g}(\rho C)_{g}+L_{s}(\rho C)_{s}\right) \frac{\partial T_{s t}}{\partial t}=h_{c d s}\left(T_{s b}-T_{s t}\right) \\
+\left(h_{c v a g}+h_{d i f g}\right) \cdot\left(T_{g t}-T_{s t}\right)
\end{array}
$$




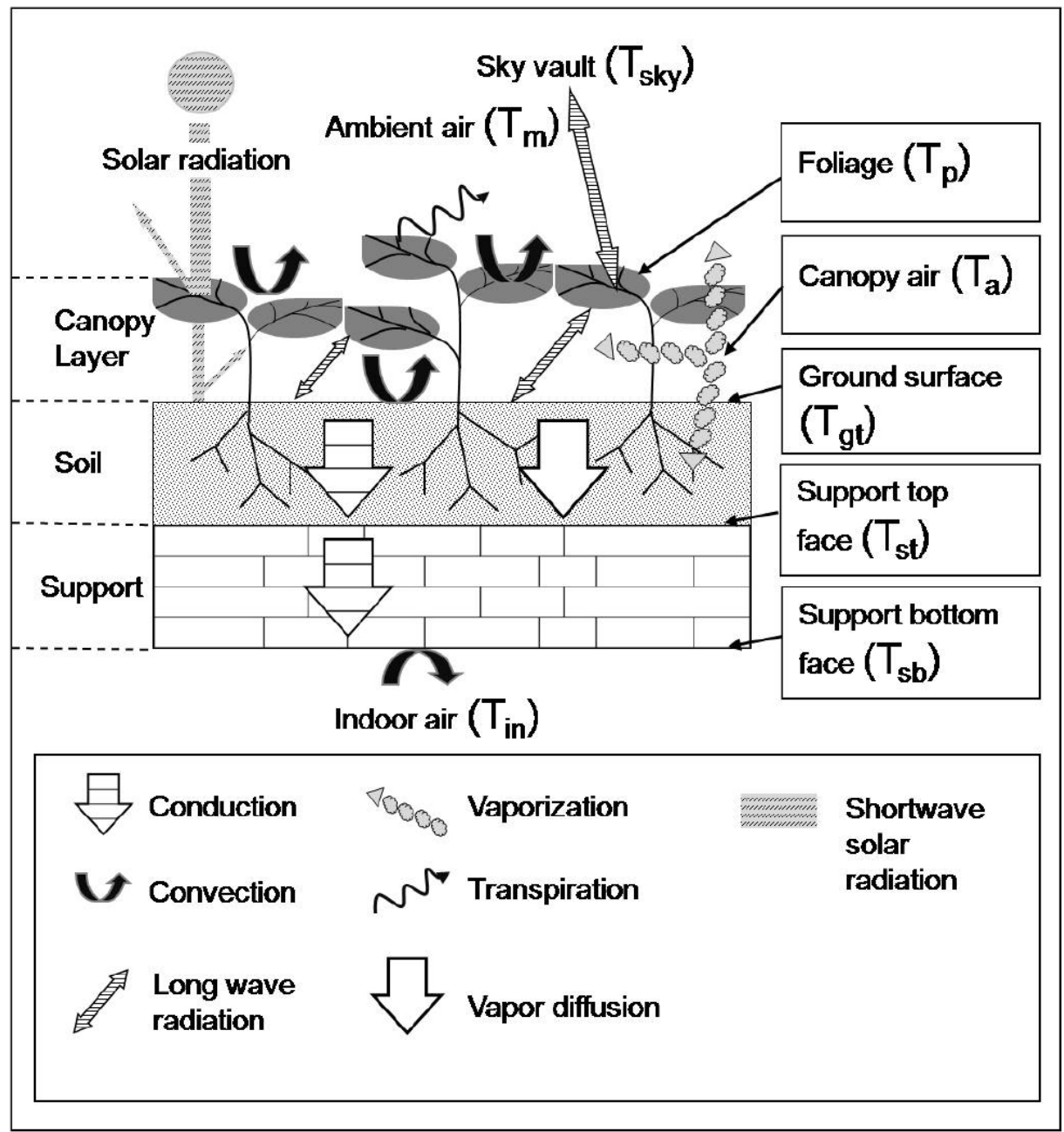

Figure 2: Thermal and mass exchanges at the level of the green roof.

At the support bottom face node

$\frac{1}{2} L_{s}(\rho C)_{s} \frac{\partial T_{s b}}{\partial t}=h_{c d s}\left(T_{s t}-T_{s b}\right)+h_{c v i n s b}\left(T_{i n}-T_{s b}\right)$

where

$T_{i}: \quad$ Temperature of the subcomponent i (see subscripts) $(K)$

$h_{t p p a}: \quad$ Thermal convective coefficient due to leaves transpiration $\left(W \cdot m^{-2}\right)$

$\varphi_{\text {vapag }}: \quad$ Vapour flux between the ground surface and the canopy air $\left(\mathrm{kg} \cdot \mathrm{m}^{-2}\right)$

$(\rho C)_{i}: \quad$ Specific heat capacity of the subcomponent $\mathrm{i}$ $\left(J \cdot m^{-3} \cdot K^{-1}\right)$

LAI: $\quad$ Leaf Area Index ( )

$d: \quad$ Average leaves thickness $(m)$
$L_{i}: \quad$ Thickness of the subcomponent i $(m)$

$\rho_{g r}: \quad$ Reflectance of the ground ( )

$\rho_{\infty}: \quad$ Reflectance of a dense canopy ( )

$\varphi_{s}: \quad$ Solar shortwave irradiance at the top of the canopy $\left(W \cdot m^{-2}\right)$

$\Lambda\left(T_{i}\right)$ : Latent heat of vaporization at the temperature $T_{i}\left(J \cdot \mathrm{kg}^{-1}\right)$

$h_{c d i}: \quad$ Thermal conductive coefficient through the subcomponent i $\left(W \cdot m^{-2} \cdot K^{-1}\right)$

$h_{c v i j}$ : Thermal convective coefficient between the subcomponents i and j $\left(W \cdot m^{-2} \cdot K^{-1}\right)$

$h_{r i j}$ : Thermal radiation coefficient between the subcomponents $\mathrm{i}$ and $\mathrm{j}$ surfaces $\left(W \cdot m^{-2} \cdot K^{-1}\right)$ 


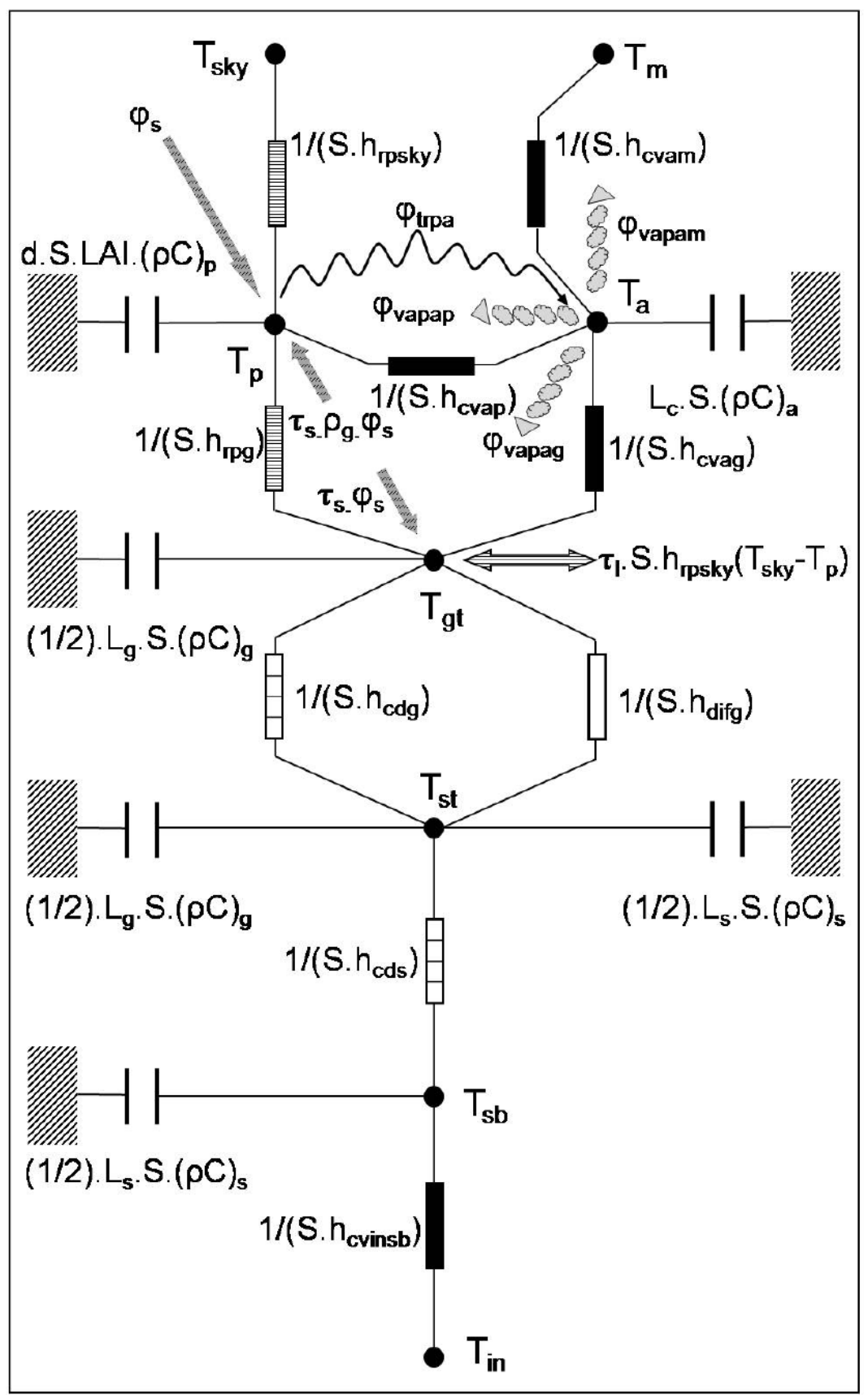

Figure 3: Equivalent electric circuit to thermal and mass exchanges at the level of the green roof.

$h_{\text {difg }}: \quad$ Non isothermal vapour transport coefficient through the ground $\left(W \cdot m^{-2} \cdot K^{-1}\right)$

$\tau_{l}: \quad$ Canopy longwave transmittance ( )

$\tau_{s}: \quad$ Canopy shortwave transmittance ( )

$\left(e_{p}-e_{a}\right)$ : Canopy leaf to air vapour pressure difference $(P a)$

The subscripts $a, g, i n, m, p, s$, sky are respectively related to the canopy air, the green roof ground ( $g t$ for its top surface), the indoor air, the outdoor ambient air, the canopy leaves, the support ( $s b$ for its bottom face and $s t$ for its top face) and the sky vault.

\subsection{Mass Balance Equation}

The ground moisture content being hypothetically considered as constant, mass balance equation is written at the level of the canopy air only:

$\rho_{a} L_{c} \frac{\partial \theta_{a}}{\partial t}=\varphi_{\text {vapap }}+\varphi_{\text {vapag }}+\varphi_{\text {vapam }}$ 
where $\theta_{a}$ and $\rho_{a}$ are respectively the canopy air specific humidity $\left(\mathrm{kg}_{\mathrm{kg}} \mathrm{kg}^{-1}\right)$ and density $\left(\mathrm{kg} . \mathrm{m}^{-3}\right), L_{c}$ is the canopy thickness $(m)$, whereas $\varphi_{\text {vapap }}, \varphi_{\text {vapag }}$, and $\varphi_{\text {vapam }}$ being the vapour fluxes between the canopy air and respectively the foliage, the ground and the outdoor air $\left(\mathrm{kg} . \mathrm{m}^{-2}\right)$, are commonly determined for $i=p, g, m$ (see subscripts in section 3.2) with the following relationship:

$\varphi_{\text {vapai }}=\frac{1}{\Lambda \gamma} h_{\text {cvai }}\left(e_{i}-e_{a}\right)$

where $\gamma$ is the thermodynamic psychrometric constant $\left(P a . K^{-1}\right), \quad h_{\text {cvai }}$ and $\left(e_{i}-e_{a}\right)$ are respectively the thermal convective coefficient $\left(W \cdot m^{-2} \cdot K^{-1}\right)$ and the partial vapour pressure deficit $(\mathrm{Pa})$ between the subcomponent i ( $i=p, g, m)$ and the canopy air.

\subsection{A Couple of Adopted Coefficients Models Related to Green Roof}

For the following equations, nomenclature given for equations (1) to (5) is still available.

- The thermal convective coefficient due to leaves transpiration $h_{\text {trpa }}$ is written as:

$h_{t r p a}=2 \cdot L A I \cdot \frac{(\rho C)_{a}}{r_{e}+r_{i}}$

where $r_{e}$ is the canopy external resistance $\left(s . m^{-1}\right)$ and $r_{i}$ is the bulk stomatal resistance $\left(s . m^{-1}\right)$. These resistances of which models proposed by the references [1, 4] were used in this survey, are vapour pressure deficit and temperature dependent.

- The non-isothermal vapour transport coefficient through the ground $h_{d i f g}$ is given by:

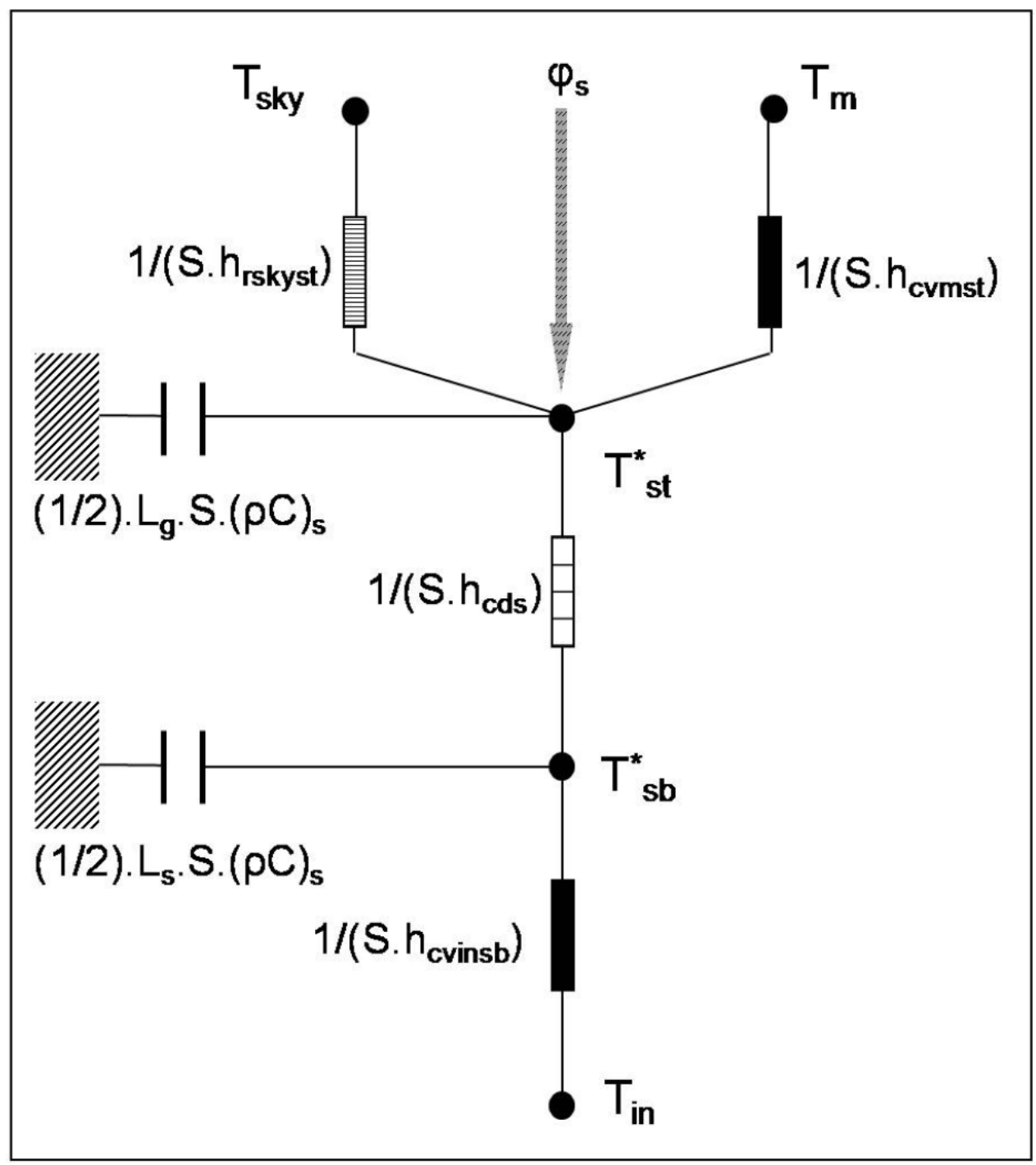

Figure 4: Equivalent electric circuit to thermal and mass exchanges at the level of the conventional roof. 


$$
h_{d i f g}=\Lambda\left(T_{g}\right) \cdot D_{v T}(w)
$$

where $D_{v T}(w)$, dependent on the volumetric moisture content $w()$ of the ground, is the non-isothermal soil vapour diffusivity coefficient $\left(\mathrm{kg} \cdot \mathrm{m}^{2} \cdot \mathrm{s}^{-1} \cdot \mathrm{K}^{-1}\right)$ of which model is described in references [11-14].

\subsection{Thermal Balance Equations of the Conventional Roof}

By removing the canopy and the ground from the green roof system, the obtained equivalent electric circuit is schematized on Figure 4. By applying the Ohm laws to every temperature node of this circuit, thermal balance equations of the conventional roof can be written as:

At the nude support top face node

$$
\begin{aligned}
& \frac{L_{s}}{2}(\rho C)_{s} \frac{\partial T_{s t}^{*}}{\partial t}=\varepsilon_{s t} \varphi_{S}+h_{c d s}\left(T_{s b}^{*}-T_{s t}^{*}\right) \\
& \quad+h_{r s k y s t}\left(T_{s k y}-T_{s t}^{*}\right)+h_{c v m s t}\left(T_{m}-T_{s t}^{*}\right)
\end{aligned}
$$

At the nude support bottom face node

$$
\frac{L_{s}}{2}(\rho C)_{s} \frac{\partial T_{s b}^{*}}{\partial t}=h_{c d s}\left(T_{s t}^{*}-T_{s b}^{*}\right)+h_{c v i n s b}\left(T_{i n}-T_{s b}^{*}\right)
$$

where, nomenclature given for equations (1) to (5) being still available, $T_{s t}^{*}$ and $T_{s b}^{*}$ are the nude support top and bottom faces temperatures respectively whereas $\varepsilon_{s t}$ is its emissivity.

\section{COMPUTING PROCEDURES}

\subsection{Model Linearization}

Before doing iterative procedure for resolving equations (1)-(6), the partial vapour pressure deficits $\left(e_{i}-e_{a}\right)$ for $i=p, g, m$ in the vapour fluxes terms of equation (7) are linearized as follows [6]:

$\left(e_{i}-e_{a}\right)=\delta_{a}\left(T^{\prime}\right)\left(T_{i}-T_{a}\right)+\left(e_{a}^{*}-e_{a}\right)$

where $\delta_{a}\left(T^{\prime}\right)$ is the slope of the vapour in air saturation curve at temperature $T^{\prime}$, with $T_{i}<T^{\prime}<T_{a}$ and $e_{a}^{*}$ is the vapour pressure of saturation $(\mathrm{Pa})$ at temperature $T_{a}$ $(K)$ of the canopy air, given by:

$e_{a}^{*}\left(T_{a}\right)=610.8 \exp \left(\frac{17.27\left(T_{a}-273.15\right)}{T_{a}-35.84}\right)$

Moreover, the vapour pressure at the canopy air $e_{a}$ can be written in term of its specific humidity $\theta_{a}$ as
$e_{a}\left(\theta_{a}\right)=\frac{P \cdot \theta_{a}}{\varepsilon+(1-\varepsilon) \theta_{a}}$

where $P$ is the barometric pressure at the roof level $(P a)$ and $\varepsilon=0.621945$.

By using Taylor extension, linearization of equations (13)-(14) can respectively be written as:

$$
\begin{aligned}
& e_{a}^{*}\left(T_{a}\right)=e_{a}^{*}\left(T_{a 0}\right)+\left.\left(T_{a}-T_{a 0}\right) \frac{\partial e_{a}^{*}\left(T_{a}\right)}{\partial T_{a}}\right|_{T_{a}=T_{a 0}} \\
& e_{a}\left(\theta_{a}\right)=e_{a}\left(\theta_{a 0}\right)+\left.\left(\theta_{a}-\theta_{a 0}\right) \frac{\partial e_{a}\left(\theta_{a}\right)}{\partial \theta_{a}}\right|_{\theta_{a}=\theta_{a 0}}
\end{aligned}
$$

where $T_{a 0}$ and $\theta_{a 0}$ are the values of $T_{a}$ and $\theta_{a}$ at the previous time step.

\subsection{Iterative Calculation Procedure}

After discretization of equations (1) - (6), an apparent linear matrix equation is obtained:

$$
A \cdot X=B
$$

which, as the non linearity source coefficients matrix $A$ is dependent on the unknown vector $X$ component variables, can be resolved by means of the following iterative calculation procedure:

a) Initialization of unknown variables values (Temperatures $T_{p}, T_{a}, T_{g t}, T_{s t}$, and $T_{s b}$ as well as canopy air specific humidity $\theta_{a}$ );

b) Calculation of coefficients matrix $A$;

c) Resolution of equation (17) by matrix inversion;

d) Vector $X$ component new values are adopted as solutions if convergence of all unknown variables is achieved; otherwise the calculation is to be resumed from the step $b$ ).

A similar iterative procedure can also be applied to solve the system of equations (10) - (11).

\section{SIMULATION AND EXPERIMENTAL RESULTS}

\subsection{Values of Model Inputs and Parameters Used for Simulations}

A series of 2 days of May $22^{\text {nd }}$ and $23^{\text {th }}, 2010$ weather data was used for simulations. The indoor air temperature $T_{i n}$ was imposed equal to $20^{\circ} \mathrm{C}$. Besides, 


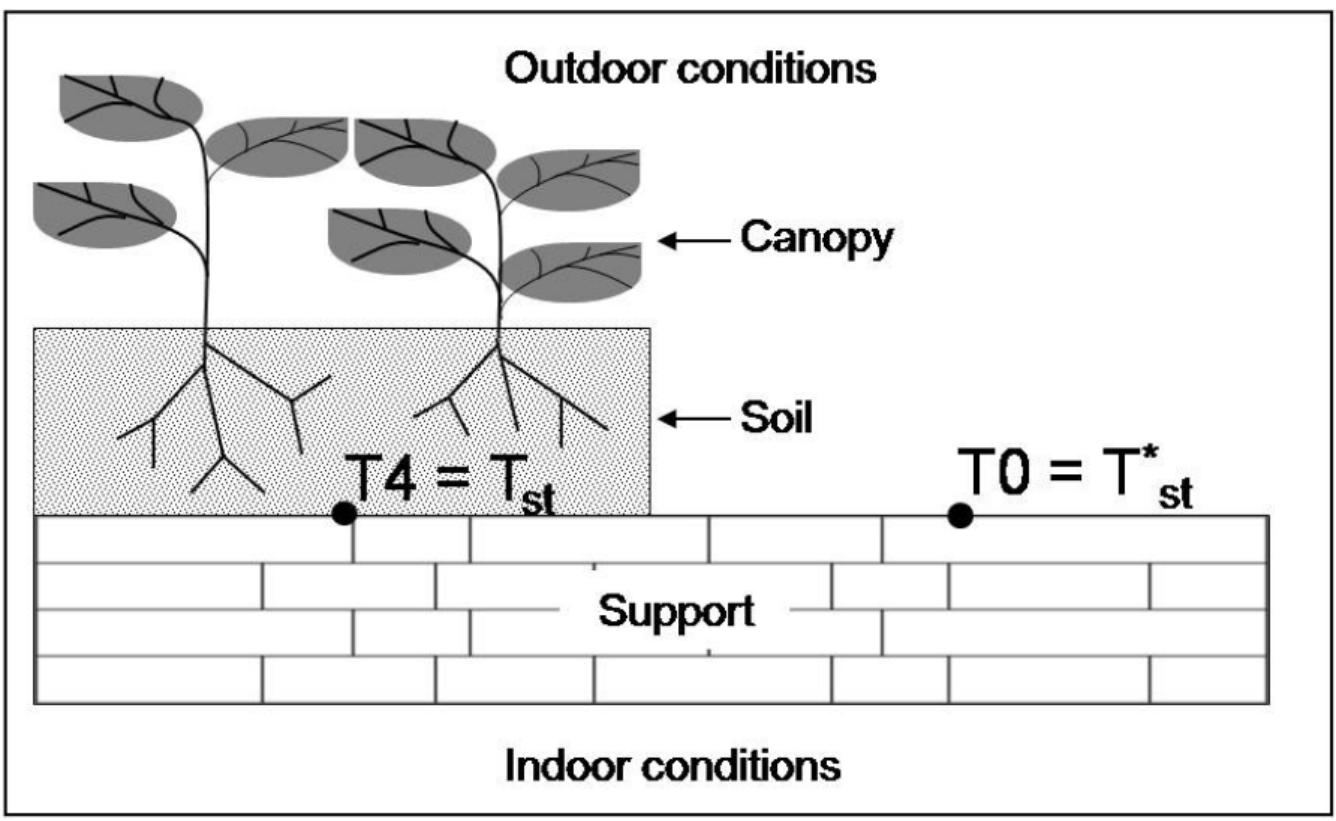

Figure 5: Arrangement of thermocouples to measure temperatures $T_{s t}^{*}=T 0$ and $T_{s t}=T 4$.

the following canopy properties values were adopted: $L A I=3, \quad k_{l}=0.8 \quad$ (longwave radiation extinction coefficient), $\quad \rho_{\infty}=0.2, \quad \tau_{l}=0.2, \quad L_{c}=0.1(\mathrm{~m})$, $d=0.001(m)$. Canopy foliage stomatal properties were assumed to be identical to those of tomatoes. The soil was supposed to have $1200\left(\mathrm{~kg} \cdot \mathrm{m}^{-3}\right)$ of apparent density, $30 \%$ of moisture content, and the following

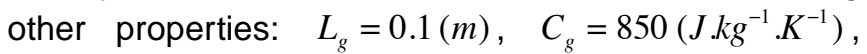
$\rho_{g r}=0.2$. The green roof support and the conventional roof were assumed to be made of the same concrete of $0.1(m)$ thick.

\subsection{Experiments Done at the Laboratory PIMENT}

Experimental measurements were done on a green roof installed at the Laboratory PIMENT of the University of La Reunion. Figure (5) illustrates the arrangement of thermocouples for measurements of temperatures $T_{s t}^{*}$ and $T_{s t}$ which were respectively noted T0 and T4 in the experimental result presentation (in section 6).

\section{RESULTS AND DISCUSSIONS}

Temperature of the green roof support top face is superior to that of the conventional roof top face in diurnal period; whereas in night-period, the opposite occurs.

That simulation result is in agreement with the experimental results obtained on May $22^{\text {nd }}$ and $23^{\text {th }}$, 2010 at the Laboratory PIMENT [15]. Indeed, although curves on Figure (7) are obtained with different weather data in wet tropical zones of Indian Ocean, they adopt an identical look. More exactly, the temperature gain $(\Delta T)$ is positive in diurnal period and is negative in night-period.

One can assert that the green roof decreases heat flux entering through the roof during the day and restrains the restoration of accumulated heat at night. The interest of green roof is so highlighted

It is notorious on Figure (6), in particular on the third subplot, that the

It is convenient to note that presentations on Figures (6 and 7) were limited to simulation and experimental results related to two following days, representing two successions of diurnal and nightperiods, to show the influence of these periods on the temperature gain.

Moreover, a sensitivity analysis of the proposed model was done by means of the FAST method (Fourier Amplitude Sensitivity Test) [14]. The temperature gain being the surveyed model output, Figures (8 and $\mathbf{9})$ respectively present the decreasing order of dominance of the most influential parameters of the model for diurnal and night periods.

In Figures (8 and 9), nomenclature given for equations (1) to (5) being still available, $\varepsilon_{i}$ is the emissivity of the subcomponent $\mathrm{i}(), \lambda_{s}$ is the thermal 


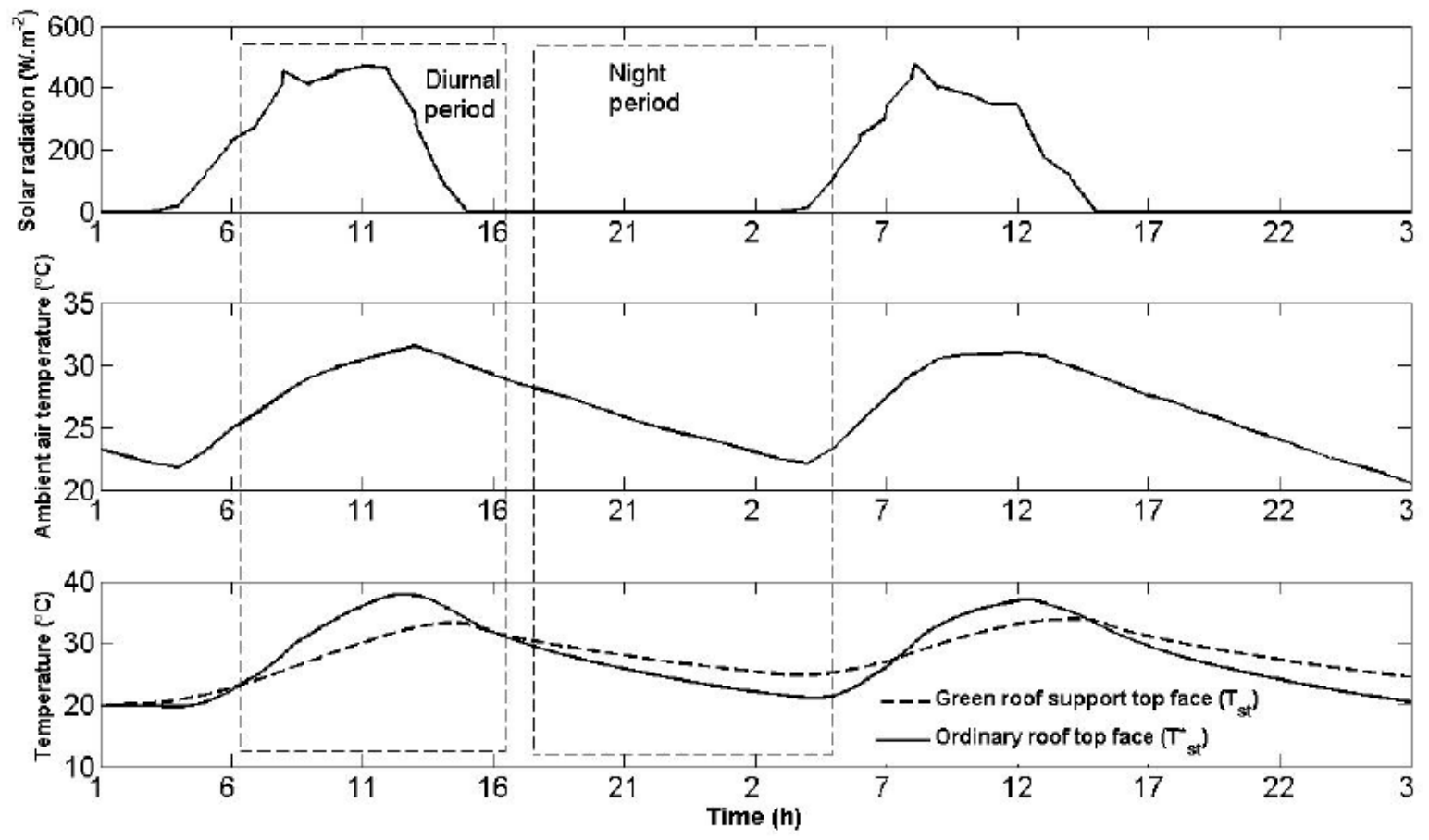

Figure 6: Green roof and conventional roof behavior comparison.

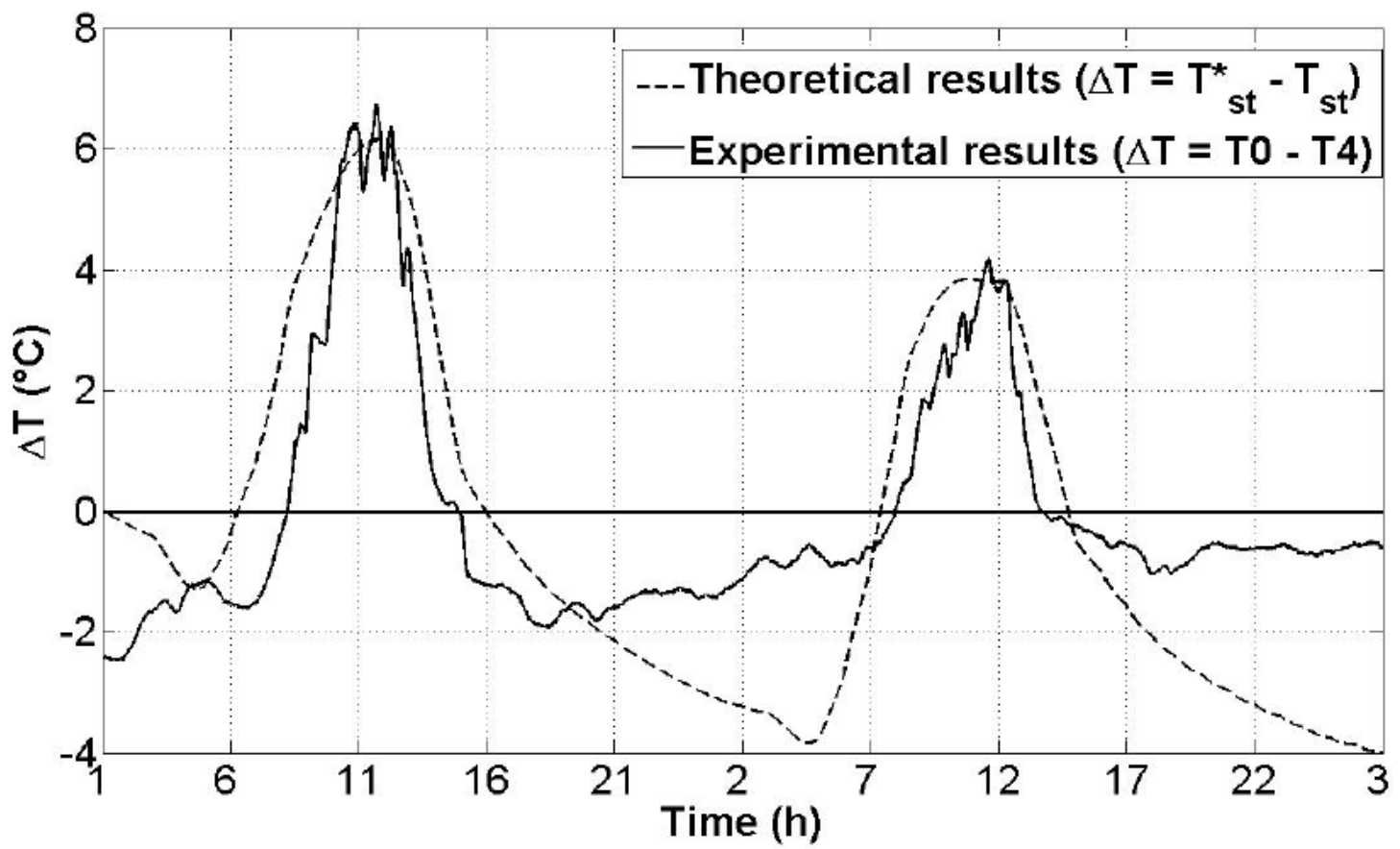

Figure 7: Comparison of the temperature gains respectively obtained from simulations and from experimental measurements at Laboratory PIMENT.

conductivity of the support $\left(W \cdot m^{-1} \cdot K^{-1}\right), C_{i}$ is the heat capacity of the subcomponent i $\left(J . \mathrm{kg}^{-1} \cdot K^{-1}\right), \rho_{s}$ is the specific gravity of particles $\left(\mathrm{kg}_{\mathrm{g}} \mathrm{m}^{-3}\right)$, difh and dirh are respectively the diffuse and direct solar radiation $\left(W . m^{-2}\right), h_{g}$ is the bulk convective heat transport between the canopy air and the ground surface
$\left(W \cdot m^{-2} \cdot K^{-1}\right), \rho$ is the apparent density of the ground $\left(\mathrm{kg} \cdot \mathrm{m}^{-3}\right)$ while $\rho_{g}$ represents its reflectance (), inclin is the inclination of the green roof $(r d), R$ is the air exchange rate $\left(s^{-1}\right), u$ is the wind speed $\left(m s^{-1}\right)$ and $f$ represents a canopy evaporating more $(f<1)$ or less $(f>1)$ than a tomato crop ( ). 


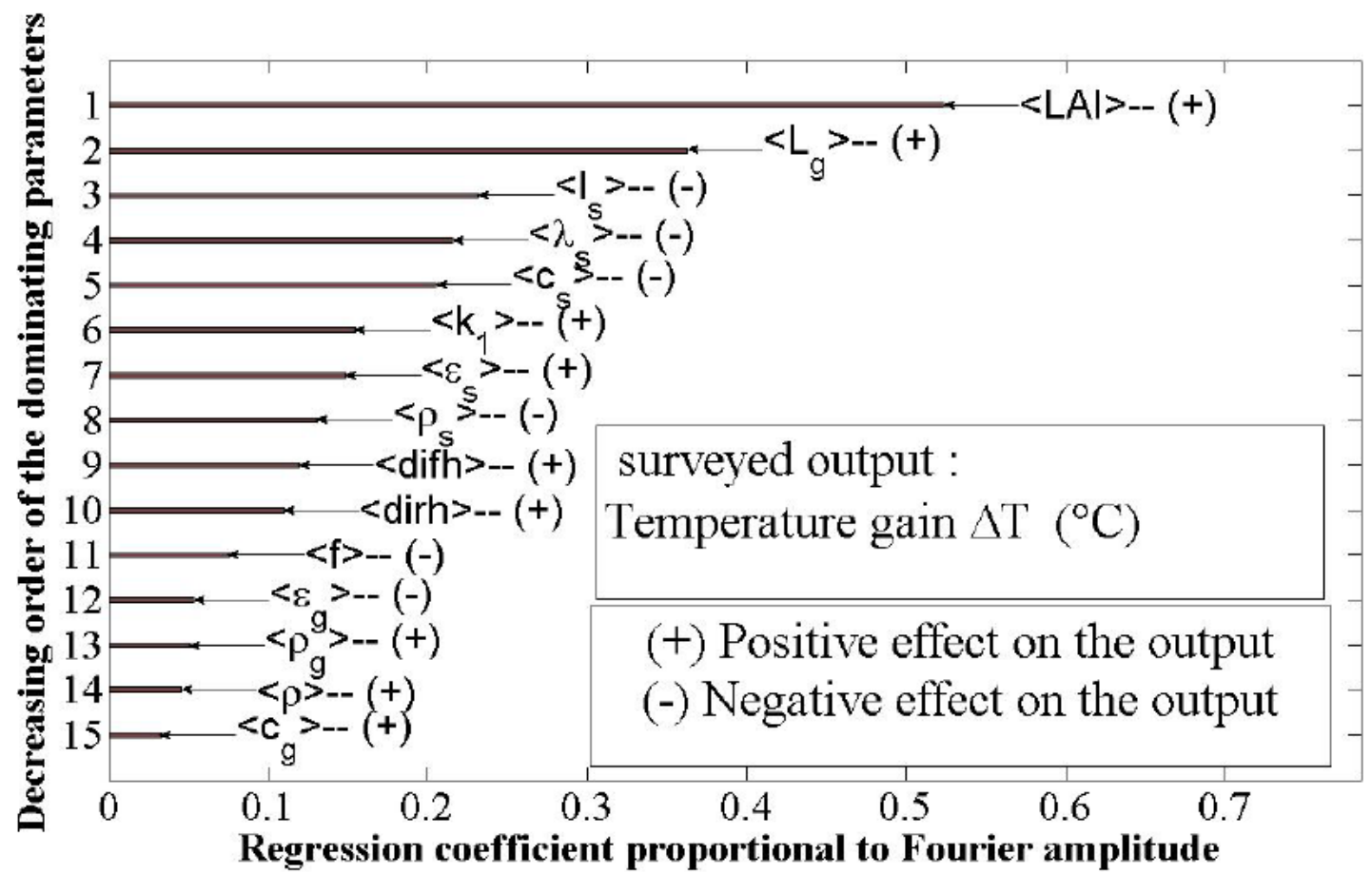

Figure 8: Comparison of the influential parameters of the proposed model during diurnal period.

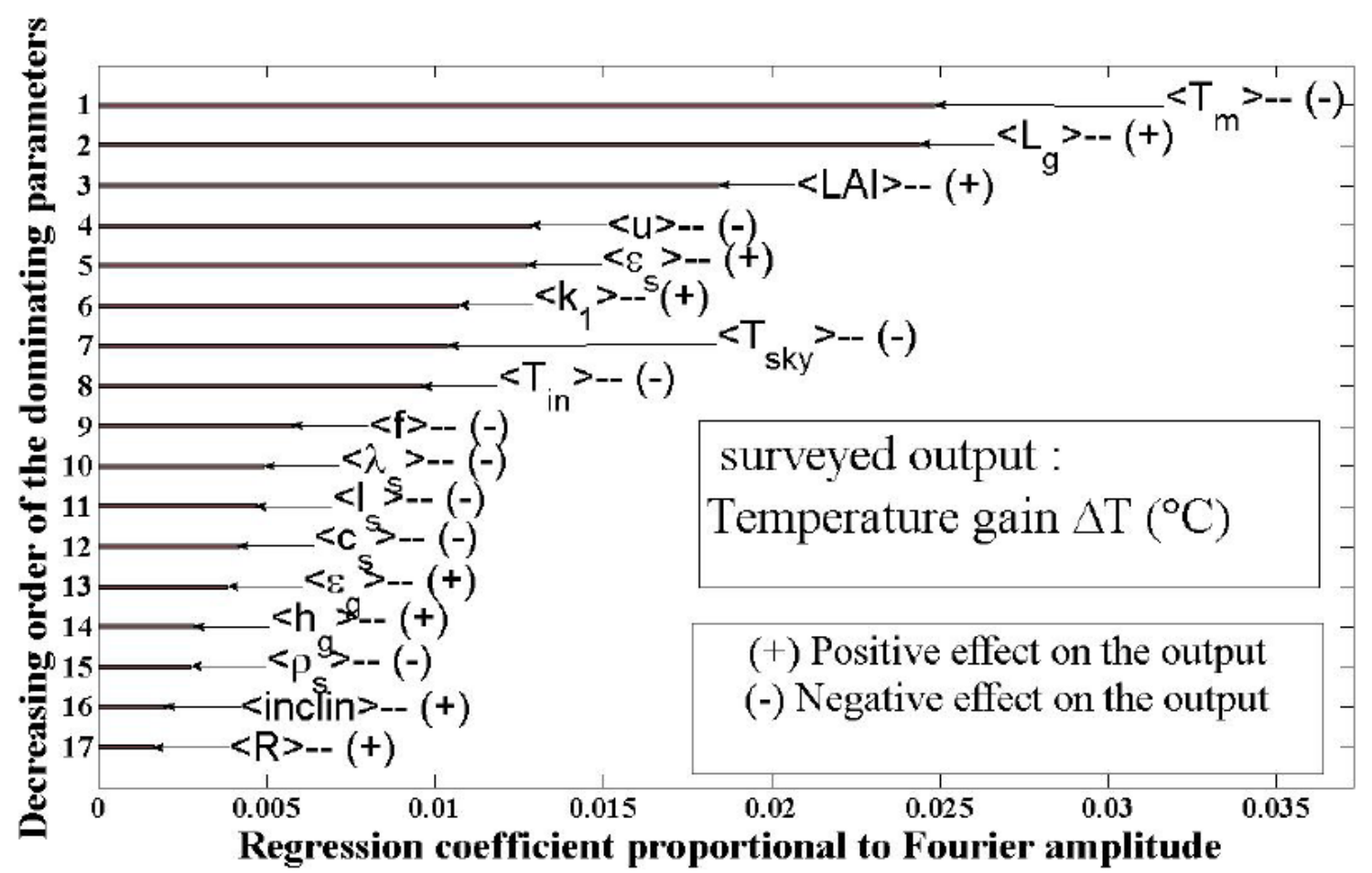

Figure 9: Comparison of the influential parameters of the proposed model during night-period.

According to Figure (8), the Leaf Area Index (LAl) is the most dominating parameter of the model during diurnal period and has a positive effect on the temperature gain $\Delta T$. Therefore, the choice of vegetation with high LAl is imperative to improve the effectiveness of green roof. This result is confirmed by the results obtained at the laboratory PIMENT. Indeed, among the three tested plants (Plectranthus, Kalanchoe, Sedum) for experimental measurements on green roof, one (Sedum) with a large LAI was the most effective [16]. Moreover, a canopy with a high longwave radiation extinction coefficient $k_{1}$ reduces also the solar radiation reaching the ground top face. With regards to the growth medium of the vegetation, it 
is important to opt for a thick layer of soil $\left(L_{g}\right)$. Indeed, the thicker is the ground, the more important is its thermal resistance. However, a reasonable thickness of ground should be chosen to avoid an excess weight which can alter the structure of the support. Besides, Figure (8) shows that diffuse and direct solar radiation have positive effect on the temperature gain in diurnal period. In other words, green roof is particularly efficient when the solar radiation is maximal, for example, during scorching heat period.

With respect to night period, it ensues from sensitivity analysis results presented on Figure (9) that the outdoor air temperature $T_{m}$ is the most influential parameter and has a negative effect on the model output $\Delta T$. It implies that the benefit of the green roof is more tangible when the outdoor air temperature is inferior to the indoor air temperature. It can also be stated that a thick layer of soil reduces heat loss through the roof whereas high values of LAI and $k_{1}$ decrease losses by radiation. A high speed of wind favors heat loss by convection on the green roof subcomponents and cools more the considered room at night.

For both periods (diurnal and night), a canopy evaporating more than a tomato crop is required.

\section{CONCLUSION}

Two mathematical models, that respectively simulate a green roof and an ordinary concrete roof, were established and presented. Having an aim of building's thermal comfort in wet tropical zones, it was necessary to highlight the benefit of the first roof type compared to the second one. For that purpose, a Matlab [17] computing code enabling to have the temperature gain, that is, the temperature difference between the green roof support top face and the same support top face but with neither vegetation nor soil on it, was worked out.

It ensues from simulation results confronted with experimental ones obtained in the Laboratory PIMENT of the University of La Reunion, that the temperature gains are positive in diurnal period and negative in night-period. Green roof can so favour energy saving in building thermal comfort process.

Results of sensitivity analysis done with FAST method enabled to identify a certain number of the most influential parameters of the proposed model, namely the canopy Leaf Area Index (LAI) and the ground layer thickness.
Besides, because of the simplicity of the proposed green roof model, its integration within a computing code simulating the thermo-hydric behavior of a whole housing environment is easy.

\section{REFERENCES}

[1] Roof Solutions for natural cooling. In: Contract $\mathrm{N}^{\circ}$ JOR3CT960074, Commission of the European Communities. DG XII, Science, Research and Development 1998.

[2] Niachou A, Papakonstantinou K, Santamouris $M$ Tsangrassoulis A, Mihalakakou G. Analysis of the green roof thermal properties and investigation of its energy performance. Energ Buildings 2001; 33: 719-29. http://dx.doi.org/10.1016/S0378-7788(01)00062-7

[3] Spala A, Bagiorgas HS, Assimakopoulos MN, Kalavrouziotis J, Matthopoulos D, Mihalakakou G. On the green roof system. Selection, state of art and energy potential investigation of a system installed in an office building in Athens, Greece. Renewable Energy 2008; 33: 173-77. http://dx.doi.org/10.1016/j.renene.2007.03.022

[4] Fioretti R, Palla A, Lanza LG, Principi P. Green roof energy and water performance in the Mediterranean climate. Build Environ 2010; 45: 1890-904. http://dx.doi.org/10.1016/j.buildenv.2010.03.001

[5] Cappelli M, Cianfrini C, Corcicone M. Effects of vegetation roof on indoor temperatures. Heat Environ 1998; 16(Pt 2): 85-90.

[6] Del Barrio EP. Roof components models simplification via statistical linearization and model reduction techniques. Energ Buildings 1999; 29(Pt 3): 259-281. http://dx.doi.org/10.1016/S0378-7788(98)00061-9

[7] Good W. Factors in planted roof design. Constr. Specific 1990; 43(Pt 11): 132.

[8] Ould-Bouthikine S, Belarbi R, Jaffal I, Trabelsi A Assessment of green roof thermal behaviour: a coupled heat and mass transfer model. Building Environ 2011. http://dx.doi:10.1016/j.buidenv.2011.06.021.

[9] Wong NH, Cheong DKW, Yan H, Soh J, Ong CL, Sia A. The effect of rooftop gardens on energy consumption of a commercial building in Singapore. Energ Buildings 2003; 35: 353-64.

http://dx.doi.org/10.1016/S0378-7788(02)00108-1

[10] Wong NH, Chen $\mathrm{Y}$, Ong CL, Sia A. Investigation of thermal benefits of rooftop garden in the tropical environment. Build Environ 2003; 38: 261-70 http://dx.doi.org/10.1016/S0360-1323(02)00066-5

[11] Del Barrio EP. Analysis of the green roofs cooling potential in buildings, Energ Buildings 1998; 27: 179-93. http://dx.doi.org/10.1016/S0378-7788(97)00029-7

[12] Rafieferantsoa MH. Mise au point d'un code de calcul pour l'étude du comportement thermique des différentes composantes d'une toiture végétalisée [M.Sc. Report]. University of Antananarivo; 2011. Available from: http://theses.recherches.gov.mg

[13] Skoutaris MP. Simulation of building's thermal behaviour with planted roof during summertime [PhD dissertation]. University of Athens; 2009. Available from: http://hdl.handle.net/123456789/3016

[14] Andriamamonjy AL. Algorithme d'automatisation de la méthode d'analyse de sensibilité globale des modèles des systèmes complexes - application sur un modèle simulan une toiture végétalisée [M.Sc. Report]. University of Antananarivo; 2012. Available from: http://theses.recherches.gov.mg 
[15] Clain A. Etude du comportement d'une toiture végétale: Instrumentation, Expérimentation et Simulation [M.Sc. Report]. University of La Reunion 2010.

[16] Morau D, Libelle T, Garde F. Performance evaluation of green roof for thermal protection of buildings in Reunion
Island. Energy Procedia 2012; 14: 1008-16. http://dx.doi.org/10.1016/j.egypro.2011.12.1047

[17] Matlab R2010a. High-performance numerical computation and visualization software, The Mathworks, Inc. 2010. 